\title{
CIÊNCIAPNATURA 35飬
}

\section{Identidade do povo indígena Guarani da cidade de Santa Maria/RS, Brasil}

\author{
Identity of the indigenous Guarani people of the city of Santa Maria / RS, Brazil
}

\author{
Geraldo Salgado Neto ${ }^{1}$
}

${ }^{1}$ Doutorando, Universidade Federal de Santa Maria. Santa Maria, Brasil

\begin{abstract}
Resumo
A identidade de um indivíduo é resultante não apenas de características pessoais inerentes á sua personalidade, mas também pelo meio social que o engloba e o insere em determinadas normas de condutas que irão fazer parte de sua visão de mundo, em nenhum momento da história dos contatos, pacíficos ou não, entre índios e brancos, no Brasil, podemos falar em um pleno apagamento dos traços identitários indígenas. Apesar das tentativas do governo colonial, bem como do imperial e republicano, os saberes culturais indígenas nunca foram completamente sobrepostos pelos modelos europeus, despertando inclusive, em determinados momentos, o interesse ou a aceitação dos colonizadores. Conhecer a identidade do povo indígena Guarani da cidade de Santa Maria/RS, a partir dos pressupostos da clínica psicossocial da identidade, se torna indispensável neste momento único da formação e agregação das primeiras reservas oficiais - aldeias Guaranis do Município de Santa Maria.
\end{abstract}

Palavras-chave: Guarani - Identidade - Indígenas - Mbyá

\begin{abstract}
The identity of an individual is the result not only of personal characteristics inherent to his personality, but also by the social environment that embraces and enters into certain standards of conduct that will be part of their world view, at no time in the history of contacts, peaceful or otherwise, between Indians and whites in Brazil, we can talk in a full erasure of indigenous identity features. Despite the attempts of the colonial government, as well as the Republican and Imperial, the indigenous cultural knowledge was never completely overlapped by European models, including waking at certain times, the interest or the acceptance of the colonizers. Knowing the identity of the indigenous Guarani people of the city of Santa Maria / RS, based on the assumptions of clinical psychosocial identity, becomes indispensable at this time only the formation and aggregation of the first official reserves Guarani tribes of the municipality of Santa Maria.
\end{abstract}

Keywords: Guarani-Identity - Indigenous - Mbyá 


\section{Introdução}

Identidade é o "sentimento do eu", o qual surge no indivíduo, através de suas identificações, suas aptidões pessoais e suas funções sociais. O sentimento de eu está ligado à congruência e á continuidade dos elementos integrados que constituem o indivíduo. São elementos que passam pela via dos impulsos instintivos, da personalidade do indivíduo e de sua integração à sociedade (Erikson, 1976). Com isso, demarca-se o processo psicossocial ao qual a constituição de uma identidade está submetida. Isso devido à identidade ser formada por um lado psíquico onde estão presentes conflitos conscientes e inconscientes, e por um lado social, onde a interação com o meio ambiente implicará em ajustes pessoais para adaptação e integração a este. Além disso, a identidade se forma e se transforma conforme o tempo; no passado estão os fundamentos de sua construção e no futuro estão as possibilidades de mudança do eu proporcionadas pela lucidez da sociedade e do indivíduo (NоAcK, 2007).

Outros autores colocam que a identidade pode ser entendida como sendo a resposta que damos a questões como: quem sou eu? De onde eu vim? Sendo que estas perguntas são de caráter individual, mas refletindo as relações estabelecidas entre o universal, o particular e o singular. Este processo é comum a todos os seres humanos, trazendo determinantes sociais e inconscientes da subjetividade (CAstoriadis, 1987; Mezan, 2002; Oliveira, 2005).

A abordagem psicossocial procura explicar como a identidade do indivíduo forma-se integralmente. A identidade de um indivíduo é resultante não apenas de características pessoais inerentes á sua personalidade, mas também pelo meio social que o engloba e o insere em determinadas normas de condutas que irão fazer parte de sua visão de mundo (Fischer, 2002).

O princípio de classificação que determina as identidades pessoais remete-nos a uma característica importante das sociedades humanas, perpassando culturas e tempos: a necessidade de nomear e representar os sujeitos, estabelecendo sentidos e significados para esses sujeitos e suas diferentes categorias. Aplicando a necessidade de classificação para o estabelecimento da identidade pessoal, BRANDÃo (1986:16) remete-nos aos princípios definidos por Marcel Mauss para o estudo da origem da ideia de pessoa:

1. como uma categoria de nominação e diferenciação de outros seres do mundo, a ideia de pessoa não é inata ao espírito humano, ela é uma produção social;

2. como outras construções simbólicas da cultura dos povos, a idéia de pessoa tem uma história própria, dentro da história social da humanidade;

3. em uma mesma época essa ideia difere de uma sociedade para a outra, podendo não existir sequer em algumas (BRANDÃo, 1986:16).

\section{Desconstrução identitária indígena}

As identidades construídas nas relações entre índios e brancos, historicamente, tenderam a depreciar o indígena. Desde o período dos "descobrimentos", momento em que duas realidades socioculturais encontraram-se, as interações entre os habitantes das terras a oeste do atlântico e os colonizadores construíram representações ou estranhamentos que relegaram a segundo plano as identidades dos chamados povos pré-colombianos. Entre as interações que redimensionaram as identidades de índios e europeus destacam se três níveis: a identidade cultural, a identidade pessoal e a identidade étnica (Braga, 2005).

Para essa afirmação, alinhamo-nos conforme a ideia de Paula Caleffi (2003:21), ao tratar da desconstrução identitária das populações pré-colombianas, iniciada no século XVI, com a chegada de Colombo ao território que o navegador genovês imaginava ser as Índias Orientais. Nesse momento, foi atribuída, pelos europeus, uma nova identidade aos grupos humanos ali existentes, generalizando-os como "índios". Essa classificação homogeneizante estabeleceu uma nova identidade, a partir da qual os índios, dali em diante assim chamados, passaram a ser representados na interação com o colonizador europeu.

A nova identidade atribuída por Colombo colocou numa mesma categoria culturas diversas e, considerando que as instituições que serviam de representação para as identidades nacionais nos século XV e XVI podiam também ser aplicadas aos grupos indígenas (língua, território tradicionalmente ocupado, história comum...), por que não dizer, nações diferentes. Essa atribuição de identidade marcou o início do processo de desconstrução da identidade cultural das populações indígenas, o qual continuou com o envio de missionários religiosos que passaram a agrupar os índios em missões, reduções e aldeamentos, para lhes apresentar a fé católica e, através da catequização, os padrões de convivência e os modelos de produção que eram interessantes ao colonizador (Braga, 2005).

A catequização foi um elemento de profunda importância na desconstrução da identidade indígena, pois, na América e, com evidência, no Brasil, entre o século XVI e o início do século XX, cristianizar, catequizar, civilizar eram parte de um mesmo processo de sobreposição dos modelos europeus aos modelos indígenas, sendo os três momentos considerados não apenas sucessivos, mas praticamente sinônimos quando aplicados à questão indígena. Por isso, o "descer índios" das serras para aldeamentos próximos do litoral, prática comum no Brasil desde o século XVI, como descrito por PerroneMoisés (1992:118), devia ser sempre acompanhado de um missionário. Reduzidos nos aldeamentos, iniciava-se o processo de sobreposição dos modelos europeus aos dos índios. "Cristianizar" pelo batismo, momento mais simbólico do que de conversão efetiva aos princípios 
religiosos cristãos, marcava o primeiro passo no processo de desconstrução da identidade indígena. A seguir, vinha o "amansar e civilizar" pela catequese, quando os índios deveriam adotar os modelos produtivos e sociais europeus, sendo assim inseridos econômica e socialmente o "índio genérico", civilizado e útil a sociedade imperial brasileira (BRAGA, 2005).

Enquanto a identidade cultural dos indígenas era desconstruída, impunha se o modus vivendi europeu. As divindades indígenas deveriam ser abandonadas, devendo os índios aceitar o batismo e a iniciação no cristianismo. Os modelos sociais de convivência nas antigas aldeias passaram a ser repelidos pelos colonizadores, que precisavam inserir os indígenas no modelo de servidão dos Estados europeus para, assim, disporem de sua mão-de-obra. Os modelos técnicos de produção, através dos quais os indígenas tradicionalmente relacionavam-se com o meio ambiente, também precisavam ser substituídos, pois as roças de subsistência dos grupos indígenas não apenas não dariam conta do volume de produção necessário à empresa da colonização, como também não estavam enquadrados nas ambições dos exploradores europeus. A substituição da religião, dos padrões de convívio e dos modelos produtivos indígenas - elementos constitutivos da identidade cultural de um povo - foram os elementos que estabeleceram os significados da conquista da América pelos europeus e reapresentaram os indígenas como inferiores. O processo pelo qual foram impostos os modelos religiosos, produtivos e de convívio social europeus representam a essência do que chamamos de desconstrução das identidades culturais indígenas (ARAúJo, 2000).

\section{Identidade indígena e as "técnicas civili- zantes"}

Entretanto, é importante destacar que, em nenhum momento da história dos contatos, pacíficos ou não, entre índios e brancos, no Brasil, podemos falar em um pleno apagamento dos traços identitários indígenas. Apesar das tentativas do governo colonial, bem como do imperial e republicano, depois dele, os saberes culturais indígenas nunca foram completamente sobrepostos pelos modelos europeus, despertando inclusive, em determinados momentos, o interesse ou a aceitação dos colonizadores. Um exemplo bastante interessante nos foi dado por Araújo (2000:54):

Já os verdadeiros tapuias, em outra parte da colônia americana, viviam de maneira diferente, na qualidade de principais responsáveis pela coleta das "drogas do sertão", como eram chamadas certas plantas - nativas e exóticas - muito utilizadas sobretudo como especiarias e para fins medicinais. [...]

Era sabido como os índios usavam para fins medicinais grande quantidade espécimes da flora. Os portugueses reconheciam-no e elogiavam seu saber. Gabriel soares de Sousa (1587), ao asseverar que "curam estes índios tupinanbás algumas postemas e bexigas com sumo de ervas de virtude que há entre eles, com que fazem muitas curas notáveis". "Duzentos anos depois VilHena (1969) também atestava que as medicinas e tintas têm a maior parte sido descobertas pelos índios, discípulos da natureza ou da necessidade". Justamente devido a essa habilidade foram empregados na tarefa de coletar as especiarias amazônicas, o que se revelou bastante eficaz com os indígenas aldeados nas missões religiosas.

Em "Viagem ao Rio Grande do Sul” (Saint-Hilaire, 1887) o naturalista francês descreve a sabedoria botânica dos índios e ao mesmo tempo cita os costumes sexuais das índias com requintes de depravação. Exemplos como esse se tornam particularmente interessantes, por apresentarem fragmentos da cultura indígena, e também no interior das missões religiosas, provenientes das práticas de pajelança e que, por isso mesmo, deveriam estar sendo combatidos pelos missionários.

Estes exemplos apresentam fragmentos da cultura indígena, provenientes das técnicas civilizantes dos missionários, ocorreram processos de desconstrução da identidade indígena, por toda América do Sul. Apesar dos métodos Europeus de desconstrução da identidade indígena, o convívio entre os nativos sempre foi um retorno a forma de vida dos antepassados. Como foi registrado por Darwin (1840) o caso do índio Yamane Jeremy Button:

No dia seguinte, depois do desjejum, Jemmy lhes deu adeus, ele não tinha "o menor desejo de retornar Inglaterra". Estava "feliz e contente", declarou, com "muitas frutas", "muitas aves", "dez guanacos" na época da neve e "bastante peixe". Ele deixou presentes tirados de sua abundância - Um par de "Belas peles de lontra", "flechas" para o capitão e "duas pontas de lança" expressamente para o senhor Darwin. Ele mesmo as havia feito. [...]. O experimento civilizatório de Fitzroy (1839) fracassara completamente, os hábitos de Jemmy (Yamane) eram arraigados, isto era óbvio, agora, por incontáveis gerações seu povo se adaptara aquela desolação e nenhuma influência civilizante poderia apagar seus instintos tão profundamente incrustados. Como seus ancestrais haviam feito durante séculos naquela "terra-dofogo" Jemmy acendeu uma fogueira de adeus... Enquanto o Beagle saia do estreito (DARwin, 1840; Desmond \& Moore, 1995; Salgado-Neto \& Salgado, 2010).

Outros demonstrativos da utilização de elementos culturais indígenas podem ser extraídos da prática das bandeiras, do comércio da erva-mate no Sul do Brasil e da intensificação na política de aldeamentos no Rio Grande do Sul, no século XIX. Nas expedições dos bandeirantes, os índios seguiam como guias, ou simplesmente como reforço bélico contra outros grupos indígenas, mas, nessa marcha, beneficiavam os integrantes 
da bandeira com seus conhecimentos sobre os recursos medicinais e alimentares do sertão. Nos ervais do Sul do Brasil, que se tornaram economicamente importantes durante os séculos XVIII e XIX, permaneceram além do hábito indígena do consumo da erva-mate, as técnicas de cultivo e manuseio da planta, sendo o índio guarani remanescente das reduções jesuíticas uma mão-de-obra bastante desejada pelos comerciantes do produto na região (LARoque, 2000). No século XIX, no Rio Grande do Sul, durante o período de intensificação da política de aldeamentos das décadas de 1840 e 1860, a ação de caciques com amplas redes de influência e parentesco entre os líderes indígenas foi de fundamental importância para o aldeamento grupos que resistiam nas sobras de mato. O exemplo mais evidente dessa aliança entre governo provincial e caciques foi destacado por LAROQUE (2000:81-148), ao abordar o caso do Cacique Doble, que atuou no convencimento dos grupos Kaingang remanescentes do norte do Rio Grande do Sul, recebendo por isso soldos, gêneros alimentícios e roupas do governo da província.

A manutenção de elementos da cultura indígena em empreendimentos movidos pela Coroa portuguesa e, depois, pelo Império brasileiro, dá importância à idéia de que as diversas frentes de expansão que se desenvolveram no Brasil aparecem como espaços de interação, entre sociedades, culturas e identidades. Enquanto as frentes de ocupação e colonização avançavam, a identidade indígena não foi passivamente desconstruída. Os índios buscaram formas de reação e articulação política, econômica e cultural com o colonizador, criando elementos híbridos, que acabaram por manter vivos traços constitutivos das identidades indígenas. As articulações entre colonizadores e índios desenvolvidas durante o contato, em que os dois lados envolvidos trocaram e passaram a adotar elementos constitutivos de identidades diferentes das suas, sublinha o caráter de interação cultural existente nos contatos entre índios e brancos, no Brasil (VAmgelista, 2000).

Um segundo nível de identidade questionado durante a conquista da América foi a própria identidade do indígena enquanto pessoa, enquanto ser humano. Entre as muitas particularidades imprimidas pela influência da Igreja na conquista, aparece o questionamento em torno da existência ou não de alma nos indígenas. Embora, nos padrões atuais, uma discussão desse porte pudesse jogar a argumentação a um nível puramente metafísico e de cientificidade duvidosa, para o período, a discussão era bastante pertinente. A classificação dos indígenas como não-humanos facilitava em muito as possibilidades de exploração dessas populações (BRAGA, 2005). A importância dessa questão pode ser constatada mais facilmente na ocupação da América espanhola, sendo bastante conhecidos os debates entre o Frei Bartolomé de Las Casas e o Doutor Sepúlveda, travados no século XVI sobre a mesma. Las Casas, que defendia a humanidade dos indígenas, assim se referia as ações dos espanhóis na América:

Os espanhóis não vão às Índias movidos pelo zelo à fé, nem pela honra de Deus, nem para servir a seu Rei como sempre se orgulham de dizer sob falsos pretextos; é a avareza e ambição que para ali os arrasta a fim de dominar perpetuamente sobre os índios, como Tiranos e Diabos, desejando que lhes sejam dados como animais. (LAs CASAs, 1996:131).

A dificuldade dos europeus em classificar o outro que ali se apresentava era interpelada ainda, como podemos perceber nas afirmações de Las Casas, pelos interesses envolvidos na conquista (LAS CASAS, 1996). O questionamento direto da possibilidade de se identificarem os indígenas como homens ganha já uma face política, configurando uma ferramenta ao justificar a subjugação daqueles "seres inferiores". As dificuldades de classificação, por parte dos europeus, daqueles seres que habitavam as terras "descobertas" não foram uma exclusividade da América espanhola. A carta de Pero Vaz de Caminha (1500), descrevendo as terras encontradas no que hoje é o Brasil, também deixou transparecer essa dificuldade. Caminha serve-nos de exemplo para uma outra característica dos processos de atribuição de identidades, a de ela se basear na carga de conhecimentos anteriores trazida pelos envolvidos na interação. A dificuldade de Caminha em descrever os indígenas não estava somente no fato de ser uma população desconhecida pelos europeus, mas também no fato de os indígenas não poderem ser associados aos padrões então conhecidos pelos exploradores, levando a descrições de um novo tipo físico, ou ao que eles não eram, como nos seguintes fragmentos do texto de Caminha, apresentados na releitura feita por Douglas Tufano (2003):

A feição deles é parda, um tanto avermelhada, com bons rostos e bons narizes, bem-feitos. Andam nus, sem nenhuma cobertura. Não fazem o menor caso de encobrir ou de mostrar suas vergonhas, e nisso têm tanta inocência como em mostrar o rosto. [...] Nenhum deles era circuncidado, mas, ao contrário, eram todos assim como nós. (TuFANo, 2003:22).

\section{4 Índio "símbolo nacional"}

Contraditoriamente, no Brasil do século XIX, a identidade pessoal dos indígenas voltou a ser questionada. No mesmo período em que o indígena foi evocado como símbolo nacional pela literatura de José de Alencar, o cientificismo questionou a controversa linha entre o que era ou não ser humano. Na tentativa de estabelecer tipos e traços característicos de humanidade, crânios de botocudos foram levados para universidades na Europa e nos Estados Unidos, onde foram examinados, na tentativa de determinar, cientificamente, se aqueles seres eram dotados de humanidade, ou apenas da aparência 
de humanos. Os resultados científicos desses exames foram ainda mais controversos. Na Europa, Blumenbach associou o crânio do botocudo ao do orangotango, enquanto, em Harvard, em 1868, Hartt considerou outro espécime de botocudo portador de um crânio plenamente "respeitável".

Certamente, esse novo questionamento da identidade humana dos indígenas chegou aos níveis políticos, servindo não apenas de retórica, mas de argumento para a derrubada de direitos adquiridos e até de extermínios. A identificação do indígena com um ser inferior e incapaz de "civilidade", tão comum na época, toma destaque na afirmação do presidente da província de Minas Gerais, em 1827, sobre os Aymorés e Botocudos:

Permita-me V. Exa. “Refletir que de Tigres só nascem Tigres; de Leões, Leões se geram; e dos cruéis Botocudos (que devoram, e bebem o sangue humano) só pode resultar prole semelhante" (Francisco Pereira de Santa Apolônia ao Visconde de São Leopoldo, 31 de março de 1827 em 1. Naud 1971:319, apud Cunha, 1992:5).

Nos estudos antropológicos, sociológicos e históricos no Brasil, principalmente a partir dos anos 1970 e 80 , reviu-se a imagem do índio que vigorava até então, baseada na ideia de que, superada sua "incapacidade relativa", o índio abandonaria os traços "bárbaros" de sua identidade de grupo, e assim estaria apto à assimilação pela sociedade nacional. Essa revisão ocorreu com a difusão da concepção de sociedades pluriétnicas, na segunda metade do século $X X$, proveniente do princípio de que o que mantém o grupo étnico é a existência da fronteira étnica e não o conteúdo nela encerrado (BRAGA, 2005). Com a ideia de manutenção das identidades de grupo, resguardadas também por fronteiras étnicas, disseminadas - primeiramente no campo acadêmico, depois nos campos político e jurídico - a cultura indígena recebeu reconhecimento, em 1988, e converteu a identidade étnica indígena em direito constitucional. O reconhecimento do grupo como portador de cultura diferenciada, no caso dos indígenas, abriu caminho para outras problemáticas mais profundas. No caso específico dos indígenas, podemos exemplificar essas problemáticas pela questão da autogestão, que implicaria reavaliação do reconhecimento da identidade nacional dos indígenas brasileiros. No âmbito geral da sociedade brasileira, salta aos olhos a questão do reconhecimento de direitos atribuídos a grupos etnicamente diferenciados, inseridos em um mesmo contexto de sociedade pluriétnica (BRAGA, 2005).

Ser índio hoje, no Brasil, passou pela classificação de uma categoria étnica e chegou aos reconhecimentos público e jurídico de indivíduos portadores de direitos por serem reconhecidos como pertencentes a uma categoria etnicamente diferenciada. A delimitação do grupo étnico a partir dos parâmetros inaugurados por Barth, na década de 60 , baseados principalmente na ideia de auto-atribuição e atribuição por outros, apareceu no Brasil com efeitos que se refletiram na Constituição de 1988. Dessa delimitação como grupo etnicamente diferenciado, e portador de direitos como tal, vieram os direitos indígenas do reconhecimento de uma sociedade e cultura; a terra; definição clara do que é terra indígena; direitos indígenas coletivos; melhores garantias para a exploração de recursos minerais e naturais em suas terras; proibição da remoção dos grupos de seus territórios tradicionais. Entretanto, como bem destacou Caleffi (2003, p. 40), o que concretamente fez da etnia uma categoria representável, na busca por direitos, foi a Constituição ter chamado os índios de índios, não mais de brasileiros, e ter garantido aos índios o direito de continuar a sê-lo.

\section{Identidade indígena a revolução cultural}

Na América existem movimentos políticos (ecológicos) e religiosos (Xamanismo Urbano) que estão engajados no propósito de um retorno gradual as formas de vida Indígenas. A problemática da identidade indígena na criação do Parque Nacional do Xingu (1961) descrito no livro "A Marcha para Oeste" (Villas-BôAs, 1994).

O primeiro registro de homem branco que se transforma em índio é de Archibald Stanfeld Belaney (18881938). Nasceu em Hastings (Inglaterra), aos dezesseis anos de idade, imigrou para o Canadá, onde foi adotado (1906) por uma tribo de índios (Ojibwe) vivendo como um nativo, gradualmente adotou o modo de vida índio.

Archie como era chamado pelos brancos, escondeu suas verdadeiras origens até um pouco antes de sua morte. Por vinte anos, viveu nas montanhas do norte de Ontário como caçador de peles, guia de caça numa aldeia indígena e guarda florestal. Em 1927, conheceu uma índia da tribo Mohawk, que se tornou seu grande amor e responsável por seu abandono à caça predatória e sua total dedicação à luta pela preservação do meio ambiente, recebeu o nome índio de Grey Owl (coruja cinzenta) e escreveu três livros famosos, morreu em 1938 em sua cabana (Beaver Lodge), local onde ainda hoje é visitado anualmente por centenas de turistas. Foi lançado o filme sobre a história de sua vida Grey Owl (1999) dirigido por Richard Attenborough.

TASSARA \& ARdans (2006) explicitam que a identidade não é algo estático, ao contrário, é um processo dinâmico que relaciona a história de vida do indivíduo com o social e ainda em um determinado espaço de tempo. Isso acaba refletindo os modelos sociais aos quais teve acesso na constituição de sua condição de homem e suas simbologias. Este artigo pretende abordar alguns importantes conceitos relativos à identidade Guarani e servir de referência para futuras pesquisas teóricas e trabalhos práticos nas áreas de Antropologia e Saúde. 


\section{Guaranis}

Guarani (denominação que significa Guerreiros), do tronco linguístico Tupi-guarani, índios que habitam ha mais de $\mathbf{1 5 0 0}$ anos a América do Sul, nordeste da Argentina, Bolívia, Uruguai e Paraguai. No Brasil ocupam os estados do sul, sudeste e Mato Grosso do Sul, do litoral até o interior. Vivem basicamente da venda de artesanatos e da agricultura de subsistência. Mesmo com quinhentos anos de contato com os brancos os Guarani conseguiram preservar importantes aspectos de sua cultura, sendo um deles a medicina. Entretanto, a falta de terras tem representado uma forte barreira no processo de sobrevivência do sistema Guarani (Teko $=$ lei, Nendé reko $=$

nosso modo de ser), que identifica etnicamente todo o grupo. Atualmente, os Guarani são obrigados a viver próximos à populações brancas e dividir espaços com outros índios, muitas vezes seus inimigos tradicionais (como é o caso dos Kaingang) (Litaiff, 1996; p. 108).

Justifica-se este projeto pelo interesse em avaliar a comunidade Guarani que habita a região central do Rio Grande do Sul, destacando os grupos étnicos particularmente interessantes. Segundo Assessoria de comunicação social, Procuradoria da República do Rio Grande do Sul -26/04/2012. Onde concedeu antecipação de tutela a uma ação do Ministério Público Federal, a Justiça Federal de Santa Maria determinou a imediata imissão de posse para a comunidade indígena do acampamento Mibyá Guarani, possibilitando que eles ocupem uma área de 77 hectares de propriedade do Estado do Rio Grande do Sul, no Distrito Industrial da cidade.

Na decisão, a juíza federal de Santa Maria Simone Barbisan Fortes determinou que os réus no processo devem providenciar remoção do acampamento indígena para a nova área, cabe a FUNAI fornecer, no menor tempo possível os materiais necessários à construção, em regime de mutirão pelos próprios indígenas. Conforme acerto ocorrido durante a inspeção judicial entre o Estado do Rio Grande do Sul, FUNAI e Município de Santa Maria.

A área escolhida já foi vistoriada e aprovada pela comunidade indígena, na inicial da ação, o procurador da República Rafael Brum Miron lembra que, conforme reconhece a própria FUNAI, a comunidade de aproximadamente quarenta indígenas, sendo quase a metade crianças, ocupava as margens da BR 392 há pelo menos trinta anos. A Ação Civil Pública corre na Justiça Federal sob o número 5005183-63.2011.404.7102/RS.

Conforme relata Rafael Brum Miron "Eles viviam espremidos entre o cercamento de imóvel particular e a rodovia federal BR 392, construíam barracos de lona sobre a faixa domínio (imóvel pertencente ao DNIT) e lá lutavam para sobreviver. Alijados de suas terras, sem espaço físico mínimo para viverem de acordo com seus costumes e tradições, não havia água encanada, energia elétrica e alimentação adequada, enfrentavam doenças, fome e desnutrição em situação de miséria absoluta".
Destaca-se a importância do presente problema de pesquisa, visto que se torna necessário compreender como se estrutura a identidade indígena para que se possa pensar em formas de intervenção junto a estas comunidades.

\section{Método}

O objetivo geral é conhecer a identidade do povo indígena Guarani da cidade de Santa Maria/RS, a partir de três pressupostos da clínica psicossocial da identidade: socioambiente, política e saúde; verificar e intervir nas necessidades dos Guaranis, dando apoio e orientação em bases psicossociais; conhecer a estrutura das comunidades nômades Guaranis; caracterizar a área de estudo (aldeias) através do mapeamento dos locais sagrados Guaranis.

O município de Santa Maria está localizado no centro geográfico do Rio Grande do Sul (2942' de latitude sul e $53^{\circ} 42^{\prime}$ de longitude oeste), onde o clima é temperado, com nevoeiros. A precipitação média anual é de 1732 $\mathrm{mm}$ e a temperatura média oscila entre $18^{\circ} \mathrm{C}$ e $20^{\circ} \mathrm{C}$ (Nimer, 1977). A cobertura vegetal característica da Floresta Estacional Decidual da Fralda da Serra Geral (Pereira et al., 1989), ocupa a zona de transição entre a depressão central do Rio Grande do Sul e a escarpa arenito-basáltica do Planalto Meridional Brasileiro, possuindo planícies aluviais, várzeas e coxilhas, com altitudes máximas de cerca de 500 metros (morros) e mínimas de 40 metros.

\section{Considerações finais}

Temos como base uma pesquisa-ação, onde os pesquisadores inserem-se no local de estudo vivenciando o dia a dia da comunidade e observando suas necessidades para assim propor uma intervenção a partir dos pressupostos da clínica psicossocial da identidade, que possam melhorar a adaptação do povo indígena Guarani na comunidade Santa-mariense e que fortifique sua identidade. Se tratando de uma pesquisa-ação o pesquisador deve sempre observar na sua participação o papel da reflexão, a necessidade de administração do conhecimento e a ética e bioética do processo (GIL, 1987).

A Análise dos dados dessa pesquisa foi feita através da abordagem qualitativa direcionada à identidade psicossocial dos Índios Guaranis habitantes da cidade de Santa Maria, através do contato direto pela pesquisa-ação procurando entender a política, a saúde e o socioambiente deste grupo em particular, seus costumes, suas canções e festas anuais. 


\section{Referências}

Assessoria de comunicação social. Procuradoria da República do Rio Grande do Sul. Índios Mbyá Guarani conquistam área de 77 hectares em Santa Maria (RS). 26/04/2012. HTTP://NOTICIAS.PGR.MPF.GOV. BR/NOTICIAS/NOTICIAS-DO SITE/COPY_OF_INDIOS-E-MINORIAS/ INDIOS-MBYA-GUARANI-CONQUISTAM-AREA-DE-77-HECTARESEM-SANTA-MARIA. Acesso em: 02/12/2012.

ARAÚJO, E. Tão vasto, tão ermo, tão longe: o sertão e o sertanejo nos tempo coloniais. In: DelPriore, M. (org.). Revisão do Paraíso: os brasileiros e o Estado em 500 anos de história. Rio de Janeiro: Campus, 2000, pp. 47-91.

BRAGA, M. A. Identidade étnica e os índios do Brasil. Métis: História \& Cultura. Vol. 4 (7) 197-212, 2005.

BRANDÃO, C. R. Identidade e etnia: construção da pessoa e resistência cultural. São Paulo: Brasiliense, 1986.

BELANEY, A. S. Pilgrims of the wild. London: Lovat Dickson \& Thompson, 1934.

CALEFFI, P. O que é ser índio hoje? A questão indígena na América Latina/Brasil no início do século XXI. Revista de Diálogos Latino-Americanos, Aarhus, n. 7, p. 20-42, 2003.

CASTORIADES, Cornelius. As encruzilhadas do labirinto II. Os domínios do homem. Tradução de José Oscar de Almeida Marques. São Paulo: Paz e Terra, 1987.

CUNHA, M. C. (Org.). Legislação indigenista do século XIX: uma compilação (1808-1889). São Paulo: Edusp, 1992.

DARWIN, Charles. The Voyage of the Beagle. London, Penguin.1840

DESMOND, A.; Moore, J. Darwin - a vida de um evolucionista atormentado. Tradução: Hamilton dos Santos, Gustavo Pereira, Maria Alice Gelman. São Paulo: Geração Editorial, 1995.

ERIKSON, E. H. Infância e sociedade. $\mathbf{2}^{\mathbf{a}}$ ed. Rio de Janeiro: Zahar, 1976.

FITZROY, R. Narrative of de surveying voyages of his majesty's ship adventure and Beagle between the 1826 and 1836, describing their examination of the Beagle's circumnavigation of the globe. London: Henry

Colburn. 1839.
FISCHER, G. N. Os conceitos fundamentais da psicologia social. Lisboa: Piaget, 1996.

GIL, Antônio Carlos. Métodos e técnicas de pesquisa social. São Paulo: Atlas, 1987.

LAROQUE, L. A. Lideranças Kaingang no Brasil meridional (1808-1889). São Leopoldo: Instituto Anchietano de Pesquisas/ Unisinos, 2000.

LAS CASAS, B. O paraíso destruído. Porto Alegre: L\&PM, 1996.

LITAIFF, A. O Sistema médico Guarani. Revista de Ciências Humanas, 14 (19): 107-115, 1996.

MEZAN, Renato. Subjetividades contemporâneas? in: Subjetividades Contemporâneas, São Paulo: Instituto Sedes Sapientiae, Ano 1, No. 1, p. 1217. [versão ampliada in: Mezan, Renato (2002) Interfaces da psicanálise. São Paulo: Companhia das Letras, p. 257-272].

NAUD, Lêda Maria Cardoso. Documentos sobre o índio brasileiro (1500-1822) In: Revista de Informação Legislativa, Brasília, 8 (29), 1971.

NIMER, E. Clima. In: Geografia do Brasil: Região Sul. IBGE Diretoria de Geociências. v. 5. Rio de Janeiro: SERGRAF/IBGE, 1977. p. 35-79.

NOACK, J. Reflexões sobre o acesso empírico da teoria da identidade de Erik H. Erikson. Interação em Psicologia, Curitiba, 11 (1) 135-146, 2007.

OLIVEIRA, B. "A dialética do singular-particularuniversal" in: Abrantes, a., da Silva, N. R. e MARTINS, S. T. Método histórico-social na psicologia social. Petrópolis: Vozes, p. 25-51, 2005.

PEREIRA, P. R. B.; Garcia Netto, L. R.; Borin, C. J. A.; Sarturi, M. G. B. Contribuição à geografia física do município de Santa Maria: unidades de paisagem. Geografia - Ensino \& Pesquisa, Santa Maria, 3: 37-68, 1989.

PERRONE-MOISÉS, B.. Índios livres e índios escravos: os princípios da legislação indigenista do período colonial (séculos XVI a XVIII). I.: Cunha, M. História dos indios do Brasil. São Paulo: Cia. das Letras, 2002.

SAINT-HILAIRE, Auguste de. Viagem ao Rio Grande do Sul. Tradução: Adroaldo Mesquita da Costa. Porto Alegre - ERUS, 1887. 
SALGADO-NETO, G.; Salgado, A. A Experiência civilizatória de Jeremy Button. Revista de Ciências Humanas, 44 (1): 249-259, 2010.

TASSARA, E.; Ardans, O. Mapeamentos, diagnósticos e intervenções participativas no campo socioambiental do Ministério do Meio Ambiente no marco do Projeto UNESCO 914/BRA 2047 - PNEA, 2006.

TUFANO, D. A viagem de Cabral na carta de Caminha. São Paulo: Moderna, 2003.

VAMGELISTA, C. Terra e fronteiras no Brasil: culturas, etnias, sociedade. História Unisinos, São Leopoldo, 4 (2): 59-72, 2000.

VILHENA, Luís dos Santos. A Bahia no século XVIII. Salvador, Itapuã,1969.

VILLAS-BÔAS, O. A marcha para oeste, a epopeia da expedição Roncador-Xingu. São Paulo: Editora Globo, 616p. 1994. 